NBER WORKING PAPER SERIES

\title{
DIFFERENTIAL MORTALITY AND THE VALUE OF INDIVIDUAL ACCOUNT RETIREMENT ANNUITIES
}

\author{
Jeffrey R. Brown \\ Working Paper 7560 \\ http://www.nber.org/papers/w7560 \\ NATIONAL BUREAU OF ECONOMIC RESEARCH \\ 1050 Massachusetts Avenue \\ Cambridge, MA 02138 \\ February 2000
}

This paper was presented at the National Bureau of Economic Research conference on Distributional Aspects of Social Security and Social Security Reform in Woodstock, Vermont on October 23, 1999. I am grateful to Peter Diamond, Martin Feldstein, Estelle James, Jeff Liebman, Olivia Mitchell, Jim Poterba, Andrew Samwick, Dimitri Vittas and NBER conference participants for helpful comments and discussions. I thank Stephanie Plancich and Joshua Pollet for excellent research assistance, and the National Institute on Aging and the National Bureau of Economic Research for financial support. The views expressed herein are those of the author and not necessarily those of the National Bureau of Economic Research.

(C) 2000 by Jeffrey R. Brown. All rights reserved. Short sections of text, not to exceed two paragraphs, may be quoted without explicit permission provided that full credit, including $\odot$ notice, is given to the source. 
Differential Mortality and the Value of Individual

Account Retirement Annuities

Jeffrey R. Brown

NBER Working Paper No. 7560

February 2000

JEL No. H55, J14

\begin{abstract}
This paper examines the extent of redistribution that would occur under various annuity and bequest options as part of an individual accounts retirement program. I first estimate mortality differentials by gender, race, ethnicity and level of education using the National Longitudinal Mortality Study and document substantial differences. I then use these estimates to examine the "expected transfers" that would take place between socioeconomic groups under different assumptions about the structure of an annuity program. Using an expected present discounted value or "money's worth" calculation as the basis for comparison, I find that the size of transfers in an individual accounts program is highly sensitive to the benefit structure. For example, mandating a single-life, real annuity can result in expected transfers of as high as $20 \%$ of the account balance, often from economically disadvantaged groups toward groups that are better off. These transfers can be substantially reduced through the use of joint life annuities, survivor provisions and bequest options. For example, the largest expected negative transfer under a joint and full survivor annuity with a fully valued 20-year guarantee option is only $2 \%$ of the account balance. However, efforts to reduce the extent of redistribution generally do so at the cost of significantly lower annuity benefits paid to the individuals who contribute to the system.
\end{abstract}

Jeffrey R. Brown

John F. Kennedy School of Government

Harvard University

79 JFK Street

Cambridge, MA 02138

and NBER

jeffrey_brown@harvard.edu 
Numerous proposals have emerged for supplementing or partially replacing the current U.S. Social Security system with a system of mandatory individual savings accounts. These accounts are designed to be like defined contribution pension plans, in that each individual would contribute a fraction of annual earnings into a retirement savings account. Upon reaching retirement, the individual would have accumulated a potentially large stock of wealth from which to finance consumption in the remaining years of life. Under such a system, a retired individual faces the problem of choosing a consumption path financed by the assets accumulated in the individual account, without incurring too great a risk of outliving available resources. One way to avoid this risk is to purchase a life annuity contract, which promises a stream of income for as long as the policyholder is alive.

This paper examines the distributional implications of alternative annuity options within a mandatory retirement savings system. Distributional considerations arise from heterogeneity in mortality risk across the population, as life annuities are structured to transfer unused resources of early decedants to longer-lived individuals. For purposes of this paper, transfers from shorterlived to longer-lived individuals should not, in and of themselves, be considered "redistribution." If everyone experienced the same risk of dying at each age, then every individual would have an equal chance of being the survivor, and thus an annuity would not redistribute in expectation. Rather, the ex-post transfers that would occur would simply be carrying out the very function of an annuity market.

This paper focuses on the redistribution that arises from differences in the expected transfers between particular demographic groups in an individual accounts system as a result of systemic mortality differences. Heterogeneity in mortality means that annuities which ignore individual or group characteristics will result in expected transfers away from high-mortality risk 
groups to low-mortality risk groups. The "groups" considered in this paper are differentiated by gender, race, Hispanic status, and level of education. I show that mortality rates differ substantially across these groups and that this leads to quite different valuations of annuities. I also demonstrate that the size of the expected transfers is quite sensitive to the specific design of the annuity program.

The extent of redistribution depends on how both the accumulation phase and the payout phase are designed. In the accumulation phase, the key question is whether or not to allow preretirement bequests. The probability of a 22-year old dying prior to retirement age and thus leaving a bequest were one permitted is very high for certain demographic groups. For example, while $20 \%$ of all 22-year old men in the year 2000 will die prior to reaching age 67 , this probability is as high as $41.2 \%$ for black males with less than a high school education, and as low as $13.1 \%$ for college educated white males. Therefore, even though lifetime earnings will be much lower for poorly educated black males, the expected discounted value of bequests for this group is $56 \%$ larger than it is for college educated white males.

Assuming an individual survives to retirement age, there are numerous dimensions along which the payout phase can be designed, including the structure of the payment trajectory, the number of lives covered, and what survivor and bequest options are included. Results indicate that the degree of redistribution that occurs within an individual accounts system is quite sensitive to the specific structure of this payout phase. Mandating the use of a single life, inflation indexed annuity leads to very substantial transfers from men to women, from blacks to whites and Hispanics, and from lower education groups to higher ones. The size of these expected transfers can be significantly reduced through the use of joint and survivor annuities, period certain or refund options, or by "front-loading" annuity payments. However, the 
mechanisms that lessen the extent of redistribution often do so at the expense of insurance provision. The way to reduce the impact of mortality differentials is to lessen the importance of mortality in the calculation of benefits. Period certain and refund options do this, but at the expense of providing a lower level of monthly income. In the extreme, one could completely eliminate redistribution by foregoing annuitization entirely. However, to do so would be to forego the potentially large welfare gains that arise from access to annuitization.

This paper is organized as follows. Section 1 examines the impact of gender, race, and educational status on mortality risk. The relevant literature on differential mortality is reviewed, and then new estimates are presented which use the National Longitudinal Mortality Study. Section 2 discusses the accumulation phase of an annuity, with particular focus on how differential mortality affects the decision of whether to allow for pre-retirement bequests.

Section 3 examines the "money's worth" of annuities for each demographic group under several different assumptions about how the payout phase is designed, including real annuities, nominal annuities, period certain options, joint life products, and refund options. I also discuss implications for variable annuity design, as well as the impact of partial or delayed annuitization. Section 4 provides a brief discussion of how the results change if we loosen the constraint that all individuals face the same price. Section 5 concludes.

\section{Mortality Differentials by Gender, Race, and Education}

\subsection{Previous Literature on Differential Mortality}

At least since the influential study by Kitagawa and Hauser (1973), it has been known that mortality differs across socioeconomic groups in the U.S. In addition to documenting the significant differences in mortality across racial lines, Kitagawa and Hauser found differences 
along educational and income margins. One of their most cited findings is that mortality varied inversely with the level of educational attainment. They found that for those aged 25 to 64 , this inverse and monotonic relationship between years of schooling and mortality existed for all race and sex classes.

In the years following this study, the literature on differential mortality has grown rapidly, and as such I will not attempt to provide a comprehensive review of this literature. ${ }^{1}$ Rather, I focus on what the literature has found with respect to four factors - gender, race, ethnicity and measures of economic status - that form the basis for the analysis that follows.

\section{$\underline{1.1 .1 \text { Gender }}$}

It is well known that mortality rates of females are lower than those of males. This differential exists at all ages in the U.S., leading to significant differences in life expectancy for men and women. The cohort used in this paper, those turning age 22 in the year 2000 , had a life expectancy at birth (in 1978) of 75.5 years for males and 82.1 years for females. To account for these differences in the analysis that follows, estimation of mortality rates will be done for males and females separately.

\section{$\underline{1.1 .2}$ Race \& Hispanic Status}

Racial and ethnic differences in mortality also exist, though there is controversy about the precise nature of these differences. It is generally agreed that mortality rates of blacks are higher than that of whites at all ages below 75, for both men and women. However, a number of studies have reported that there exists a mortality "crossover" between blacks and whites at older ages, meaning that black mortality rates fall below those of whites at older ages (Sorlie et al, 1992). Yet other authors have concluded that the racial crossover does not exist, but rather is a result of

\footnotetext{
${ }^{1}$ Readers interested in a more complete review of the literature should consult Feinstein (1993).
} 
"serious errors and inconsistencies in the data on which national estimates of African-American mortality at older ages are based" (Preston et al 1996). The ages reported on death certificates appear to be systematically younger than those reported in the U.S. Census. As a result, when researchers correct for this misreporting bias, the racial crossover in mortality disappears. If the racial crossover exists before or shortly after retirement, it is potentially important for understanding how blacks fare relative to whites under alternative annuitization schemes. While resolving this conflict is beyond the scope of this paper, I find little evidence of racial crossover in the data and therefore make no corrections in the analysis that follows.

While research on the mortality experience of Hispanics is more limited, available evidence suggests that U.S. Hispanics have lower mortality rates than non-Hispanic whites, despite a greater proportion of Hispanics living in poverty, lacking health insurance, and having more limited access to health care (Sorlie, et al 1993). Hispanics tend to have lower rates of heart disease, cancer, and pulmonary disease, though these differences do not seem to be explained by the major known risk factors for these diseases, suggesting perhaps a genetic or biological explanation. However, there are several reasons to suspect that some of the observed difference is not real, but rather due to sampling bias. For example, if sampling techniques tend to under-sample less healthy Hispanics (e.g., migrant farm workers), this would bias mortality rates down. In addition, studies like the National Longitudinal Mortality Study used in this paper obtain mortality information by linking to the National Death Index. This means that deaths outside of the U.S. are not recorded in the NDI, and therefore some individuals' deaths will be missed. One researcher has labeled this effect the "Salmon bias," due to the "compulsion to die in one's birthplace" leading to a bias in mortality rates (Pablos-Mendez 1994). In the NLMS data, I find that mortality rates for Hispanic women are, in fact, significantly lower than those for 
white women at most ages. For Hispanic men, the data indicates that mortality rates tend to be slightly higher than for white men at most ages.

It should also be noted that there is substantial heterogeneity within the Hispanic population. Of particular importance is the fact that foreign-born persons tend to have lower mortality risk than native-born persons. (Sorlie, et al, 1993). Because a large fraction of the U.S. Hispanic population is foreign born, this "healthy migrant effect" may partially explain the lower mortality rates among Hispanics. Projecting forward, if native-born segment of the U.S. Hispanic population increases as a share of the total Hispanic population, these mortality differentials may decrease.

\subsubsection{Economic Status}

A third factor that is significantly correlated with mortality is an individual's economic status. The evidence suggests that individuals who are in a higher socioeconomic group tend to live longer. There is, however, no definitive way to measure these effects. Three measures of economic status are used in the literature, namely education, income, and wealth, and each is subject to its own limitations. ${ }^{2}$

A significant negative correlation between education and mortality is nearly always found (Kitawaga \& Hauser 1973, Deaton \& Paxson 1999, Lantz et al 1998). This could be due to the fact that education serves as a rough proxy for lifetime earnings, and hence picks up the fact that people with more resources tend to live longer. On the other hand, there could be a very direct effect of education on mortality, if for example, more highly educated individuals better understand the risks of certain behaviors and avoid them as a result. In this paper, I will use education as the only proxy for lifetime resources. This choice is driven in part by a belief that

\footnotetext{
${ }^{2}$ Smith (1999) provides an excellent discussion of the issues involved in understanding these relationships.
} 
education is a better proxy for lifetime resources than other measures, and in part by necessity the NLMS income data are of questionable value, and wealth data do not exist.

A second widely used indicator of economic status is a measure of individual or family current income. Again, a significant negative correlation between income and mortality is universally found (for example, Kitawaga \& Hauser 1973, Hadley \& Osei 1982, Lantz et al 1998, Kaplan 1996, Deaton \& Paxson 1999). In fact, many of these studies indicate that income and education have independent effects. However, current income is a poor measure of lifetime resources for several reasons. The most important criticism of this approach is the problem of simultaneous causation between income and health. Low-income individuals are more likely to suffer from health problems and thus experience higher mortality rates. But it is also true that individuals in poor health may be unable to earn a high income, in which case the causality of the relationship is reversed. As a result, it is quite difficult to provide any causal interpretation to the coefficient in a simple regression of mortality rates on current income.

A third measure of socioeconomic status that is used in the literature is wealth. Attanasio \& Hoynes (1995), Menchik (1993), and Palmer (1989) all provide compelling evidence that wealth and mortality are inversely correlated. The use of wealth partially addresses the simultaneity problem that arises when using current income, since presumably wealth accumulation is less affected by health problems. However, as noted by Attanasio \& Hoynes (1995), wealth cannot be considered a purely exogenous variable, both because of correlation with health, and because wealth accumulation behavior of individuals with different life expectancies could be different. 


\subsection{Previous Literature on Social Security and Differential Mortality}

The importance of differential mortality has not gone unnoticed in the economics literature, especially with regard to its impact on Social Security. It has long been recognized that high income individuals might receive relatively higher benefits relative to taxes paid than low income individuals if they have a higher life expectancy. A spate of recent studies (Liebman 1999, Panis \& Lillard 1996, Duggan et al 1995, and Garrett 1995) have investigated the progressivity of the existing Social Security benefit system making use of mortality differences by economic factors. These authors agree that there are significant correlations between measures of economic well-being and mortality. However, while authors such as Garrett find that mortality differences are sufficient to eliminate the progressive returns, Duggan et al conclude that the effect of income on mortality is not sufficient to overturn the progressivity.

All of the aforementioned papers have focused primarily on the impact of differential mortality on the existing Social Security system. However, these have limited applicability in quantifying the distributional impact of an individual accounts system. There are at least three distinct factors that affect the progressivity of the current system - a regressive payroll tax, a progressive benefit formula, and differential mortality. Most of the proposed individual account programs do not involve progressive benefit formulas, and so the potentially regressive effects of differential mortality may have a much more direct impact on such a system. This paper, along with recent work by Feldstein \& Liebman (2000, this volume), is among the first papers to explore the implications of mortality differentials within the specific context of an individual account system. 


\subsection{Estimates of Differential Mortality Using the NLMS}

Rather than piecing together estimates of the impact of gender, race, and economic status on mortality from several disparate sources, this paper uses new estimates from the National Longitudinal Mortality Survey. The NLMS is a survey of individuals who were originally included in the Current Population Survey and/or the Census in the late 1970s and early 1980s. Throughout the 1980s, death certificate information from the National Death Index was merged back into the survey data, allowing researchers to compare the death rates of individuals on the basis of demographic characteristics at the time of the interview.

I construct age-specific mortality estimates from the NLMS based on gender, race, ethnicity, and educational attainment. ${ }^{3}$ I first construct separate mortality rates for black, white, and Hispanic males and females, a total of 6 groups. I then further differentiate whites and blacks into three education groups, namely less than high school, high school plus up to three years of college, and college graduates. Due to small sample sizes, it is not possible to differentiate Hispanics along educational lines. While the NLMS data does include a measure of family income in 1980, I do not make use of this information due to the problem of simultaneous causation.

Several steps are required to use the NLMS to construct complete cohort mortality tables for specific groups. The first step is to split the NLMS sample into separate groups based on the gender, race, ethnic and education categories. For each group g the age-specific non-parametric (np) mortality rate, $\mathrm{q}_{\mathrm{x}, \mathrm{g}}^{\mathrm{np}}$, is calculated as the fraction of those individuals age $\mathrm{x}$ who die before

\footnotetext{
${ }^{3}$ The mortality estimates used in this paper were constructed in joint work with Jeff Liebman, with assistance from Joshua Pollet. Additional detail on the construction of these estimates will be made available in a forthcoming data appendix.
} 
attaining age $x+1$. This procedure provides a simple, non-parametric estimate of the age specific mortality rate for individuals with the characteristics of group $\mathrm{g}$.

There are several reasons why one does not want to stop here and simply use these nonparametric estimates. First, sample sizes are quite small in some groups (e.g., college educated black men) at many ages, and therefore the point-estimates are noisy and even non-monotonic with age, which is clearly inconsistent with known actuarial experience. Second, even if the NLMS data perfectly represented the population alive in 1980, this approach would only provide a 1980 "period" mortality table, or the mortality experience of individuals alive in 1980 . For purposes of this study, the table of interest is a "cohort" mortality table that represents the mortality experience of individuals born in a particular year. The difference between these two tables arises from the fact that mortality rates have historically improved over time. Thus, some method of conversion from a 1980 period table to a particular birth cohort table is required. Third, the NLMS study is not fully representative of the entire US population, in part because it excludes the institutionalized population and thus understates overall mortality rates. Therefore, while the NLMS may contain valuable information about the relative mortality rates of various groups, it is unlikely to provide accurate information about the absolute levels of mortality for the population as a whole.

In order to address these concerns, several additional steps are required. In order to correct for non-monotonicity, the non-parametric estimates, $\mathrm{q}_{\mathrm{x}, \mathrm{g}}^{\mathrm{np}}$, are treated as the independent variable in a non-linear least squares regression on age $\mathrm{x}$. The non-linear regression is used to estimate three parameters of a Gompertz/Makeham survival function. As explained in Jordan (1991), with the proper choice of the three parameters, this formula can be applied from about age 20 almost to the end of life. The Gompertz/Makeham formula used is: 


$$
l_{x}=k s^{x} g^{c^{x}}
$$

$$
\text { where } k=\frac{l_{0}}{g} \text { and } q_{x}=\frac{l_{x+1}-l_{x}}{l_{x}}
$$

$\mathrm{x}$ is age, and $\mathrm{g}, \mathrm{c}$, and $\mathrm{s}$ are the parameters to be estimated. Note that if $1_{0}$ is set equal to one, then $1_{\mathrm{x}}$ is simply the cumulative survival probability at age $\mathrm{x}$. Using the regression estimates of $\mathrm{g}, \mathrm{c}$, and $\mathrm{s}$, one then has a "Makeham formula" that gives mortality $\mathrm{q}_{\mathrm{x}}$ as a function of $\mathrm{x}$. Let us denote these fitted values of mortality for group $g$ at age $x$ as $\mathrm{q}^{\mathrm{fit}}{ }_{\mathrm{x}, \mathrm{g}}$. An important feature of this approach is that fitted mortality rates are a monotonically increasing function of age $\mathrm{x}$. Another feature is that it allows one to create out-of-sample estimates of mortality. Therefore, while I only use data from age 25 to 84 to fit the curve, I can then use the formula to provide us with estimates of mortality for ages outside of this range.

Once these predicted mortality rates are in hand, the next step is to convert them into cohort life tables for each group by making two related assumptions. The first is that the ratios of a group's age-specific mortality to that of the population as a whole $\left(\mathrm{q}_{\mathrm{x}, \mathrm{g}} / \mathrm{q}_{\mathrm{x}}\right)$ in the NLMS sample is an accurate portrayal of these ratios in the full population in 1980. The second assumption is that these ratios are constant over time. By invoking these two assumptions, it is possible to then construct a group specific cohort life tables for any year.

Specifically, let $\mathrm{q}_{\mathrm{x}, \mathrm{g}}^{\mathrm{fit}}$ be the fitted value of the mortality rate for an individual age $\mathrm{x}$ belonging to group $\mathrm{g}$, and let $\mathrm{q}^{\mathrm{fit}}{ }_{\mathrm{x}}$ be the mortality rate for an individual age $\mathrm{x}$ for the population as a whole, both from the fitted NLMS data. Let $\mathrm{q}_{\mathrm{x}}^{\mathrm{SSA}}$ be the age-specific mortality rate from the 1978 birth cohort table from the Social Security Administration, which represents individuals turning age 22 in the year 2000. Then the cohort, group specific mortality rates that I will use are constructed as follows: 


$$
q_{x, g}^{S S A}=q_{x}^{S S A} \frac{q_{x, g}^{f i t}}{q_{x}^{f i t}}
$$

The one exception to this methodology is that in the case of college and high school educated black males and females, I assumed that the mortality ratio between education groups was the same for blacks as for whites. I then applied the white education ratio to the fitted q's for blacks in order to construct the estimates for higher educated blacks. This was done because the sample sizes at many ages were too small for these black education groups to reliably construct an independent estimate.

Table 1 reports how the age to which a 22 year old in the year 2000 can expect to live varies by the gender, race, ethnicity, and education as calculated using the above methods. The average 22 year old male can expect to live to age 77.4 , while the average 22 year old woman can expect to live to age 83.4 . However, these estimates vary widely by race. White, black, and Hispanic 22-year old males have life expectancies of 78.3, 71.8 and 77.4 years respectively, while white, black and Hispanic females have life expectancies of 84.0, 80.0, and 85.2 years respectively.

Life expectancy conditional on reaching age 22 also varies substantially by education level. 22 year old white men with less than a high school education can expect to live to age 75.3 years, a full 5.2 years less than that of a white male with a college degree. Low educated black males have by far the lowest conditional life expectancy of any group examined, at 68.1 years. The highest conditional life expectancy is college educated white women, who can expect to live to age 87.8 .

Two partially offsetting limitations of these mortality differentials should be noted. First, using education as a proxy for lifetime earnings may actually understate the extent to which mortality rates differ across socioeconomic groups. Deaton \& Paxson (1999) suggest that even 
after controlling for education, income differentials may continue to have an independent effect on mortality. Second, these results do not differentiate based on disability status. Disabled individuals experience higher mortality rates than the non-disabled population. To the extent that disability status is correlated with gender, race, ethnicity, and education, the estimates presented here may be attributing too much of the mortality differential to these factors.

Because a life annuity is a financial vehicle that pays income contingent on the individual being alive, people with longer life expectancies generally expect to receive more annuity income than individuals with shorter life expectancies. These differences suggest that demographic groups with lower average life expectancies will fare poorly under an annuity rule that mandates the use of a single annuity conversion factor, or a single price, for all individuals of the same age. However, these differences can vary substantially based on the specific form that the annuity takes. Therefore, the next Section discusses annuities in more detail.

\section{The Accumulation Phase}

In general, there are two phases to an individual accounts retirement system. The "accumulation phase" corresponds to an individual's working life, when he or she is contributing a portion of earnings to an account that is invested in a diversified portfolio of securities. Then, upon retirement, the individual stops contributing to the account and starts the "payout phase" in order to finance retirement consumption. ${ }^{4}$ The design of each of these phases has potentially important distributional effects. This section discusses the issues involved in the accumulation phase of the account. Section 3 discusses payout options.

\footnotetext{
${ }^{4}$ The accumulation and payout phases may overlap in some cases, such as when an individual begins a partial annuitization process prior to retirement. For an example of this, see Kotlikoff \& Sachs, 1998.
} 
The central question in the accumulation phase from a distributional perspective is what happens to the balance of an individual account upon the pre-retirement death of a worker. There are two options. First, the account may be considered part of the decedant's estate, and thus be made available to the individual's family or other beneficiaries. Second, the account could become the "property" of the Social Security system and redistributed to the remaining workers in the system. In this latter case, the contributions made by early decedants are used to increase the rate of return to other participants in the system.

Let $\mathrm{q}_{\mathrm{x}}$ represent the annual mortality rate for an individual of age $\mathrm{x}$, and let $\mathrm{r}$ be the rate of return on investments in an individual account. For simplicity, let us assume that $\mathrm{r}$ is fixed. Under the first option, whereby the account balance is bequeathable, the gross annual rate of return on the account is simply $1+\mathrm{r}$ for all participants. If an individual contributes $\$ 1$ at the beginning of the year and survives, he will have $1+\mathrm{r}$ dollars in his account at the end of the year. If he dies, his estate will have a value of $1+r$ dollars at the end of the year. In the second case, in which the assets of deceased participants are redistributed to remaining participants, the gross annual rate of return on the account, which I will call $(1+\mathrm{R})$, is as follows:

$$
1+R=\left\{\begin{array}{c}
\frac{1+r}{1-q_{x}} \text { if alive } \\
0 \quad \text { otherwise }
\end{array}\right.
$$

The $\left(1-q_{x}\right)$ factor in the denominator is the amount by which the return is increased to survivors. Thus, if the investment rate of return is $5 \%$, and $1 \%$ of the population dies during the year, the account balance of survivors would increase by $6.06 \%$ in that year. Feldstein \& Ranguelova (1999) have shown that over the course of a lifetime, the cumulative effect of allowing pre- 
retirement bequests as part of a "Personal Security Accounts" system is to decrease the mean accumulation of assets at retirement by $14 \%$.

Therefore, the question of whether or not to allow bequests boils down to a choice between providing wealth to estate beneficiaries or providing higher rates of returns to those who live a long time. In thinking about the relative importance of bequests across groups, one must consider two factors, namely the relative size of accounts (the "income effect") and the probability of dying before retirement age (the "mortality effect"). Individuals with large account accumulations and with a high probability of dying before retirement will benefit the most from the bequest option. However, these two factors often work in different directions, i.e., individuals with larger account balances are likely to have lower mortality rates, due to the inverse correlation between economic status and mortality.

In order to estimate the net effect of allowing bequests, I have constructed a measure of the expected, discounted value of bequests for each of the racial/ethnic/education groups as follows: Suppose an "average" male enters the labor force at age 22, earning annual income $I_{22}$. Assume that annual income increases each year at a real rate of $1+\mathrm{g}$, so that

$$
I_{a}=I_{22} \cdot(1+g)^{a-22}
$$

where $a$ represents the individual's age. Assume that $\alpha$ is the fraction of income that is saved in an individual account each year, and that the account earns a real rate of interest $r$. If $\mathrm{q}_{\mathrm{a}}$ represents the mortality rate at age $a$, and $\mathrm{P}_{\mathrm{a}}$ represents the cumulative probability of surviving from age 22 to age $a$, then the expected present discounted value of future bequests is:

$$
\text { EPDV of Bequest }=\alpha \cdot I_{22} \cdot \sum_{a=22}^{67} \frac{\left(P_{a-1} \cdot q_{a} \cdot \sum_{s=1}^{a-21}(1+g)^{s-1}(1+r)^{a-20-s}\right)}{(1+r)^{a-21}}
$$


If we assume that $\alpha, \mathrm{g}$, and $\mathrm{r}$ are the same for all groups, then differences in the expected present discounted value of bequests will arise from differences in mortality rates $\left(\mathrm{P}_{\mathrm{a}}\right.$ and $\left.\mathrm{q}_{\mathrm{a}}\right)$ and differences in the level of income $\left(\mathrm{I}_{22}\right)$.

To parameterize the income effect, i.e., differences in $\mathrm{I}_{22}$, I use the Social Security earnings records from the restricted data supplement to the Health and Retirement Survey (HRS). Specifically, I take the ratio of the mean Average Indexed Monthly Earnings (AIME) for males in each socioeconomic group to the mean AIME for all males (using HRS population weights). These ratios are reported in column 1 of Table 2. As these results indicate, there are substantial differences in the level of income earned by each group, with the average white male earning $6 \%$ more, the average black male earning $30 \%$ less, and the average Hispanic male earning $28 \%$ less than the average for all three groups combined. ${ }^{5}$ For purposes of calculations in table 2 , I will assume that these differences in AIME are indicative of a constant difference in annual earnings throughout one's working life. In other words, I use these ratios to shift the entire income path up and down, and assume that the slope of the income path (g in equations 4 and 5 above) is the same for all groups.

Columns 2 through 6 of Table 2 report the cumulative probability of leaving a bequest at ages $30,40,50,60$, and 67 . These figures provide some insight into the "mortality effect" on bequests, namely that holding account size equal, the expected value of bequests will be higher for individuals with higher mortality rates. As these columns indicate, there is substantial heterogeneity in the cumulative probabilities at all ages.

\footnotetext{
${ }^{5}$ These numbers reflect the AIME as of the survey date, when most of these individuals were still between the ages of 51 and 61, and thus still in the labor force. Thus, these figures should be considered only a "rough approximation" as they do not control for differences in the age composition of each demographic group.
} 
Column 7 reports the expected present discounted value of bequests using equation 5 above, setting $\mathrm{g}=.01, \mathrm{r}=.03, \alpha=.06$, and $\mathrm{I}_{22}=\$ 30,000$. As can be seen the expected present discounted value of bequests for each group lies in between $\$ 5,932$ and $\$ 10,205$. These rather small expected present values mask that fact that, conditional on dying and leaving a bequest, the average bequest size can be substantial. For example, with a riskless real interest rate of only $3 \%$, the account balance of an "average" male would grow to over $\$ 200,000$ before retirement. Feldstein and Ranguelova (1999) show that an individual investing in a mixed portfolio of bonds and equities would have an expected account size at retirement of nearly $\$ 500,000$. However, when these large bequests are discounted and multiplied by the relatively small probability of dying at each age, the expected present value of the average bequest is only $\$ 8,306$.

The final column of Table 2 provides a simple metric by which to compare the importance of bequests across groups, which is the ratio of the expected discounted value of bequests for each group to that of the average male. As a starting point for interpreting these results, let us begin by comparing whites and blacks, without differentiating by educational attainment. Looking at column 1 we again see that whites have higher earnings than blacks, and therefore will (holding $\alpha$ and $\mathrm{r}$ equal) have higher individual account balances to bequeath. However, the probability of a black male dying and leaving a bequest is substantially higher than that of a white male. The net effect is that the expected present value of bequests is approximately $4 \%$ higher for black men than white men (\$8504 vs. \$8178).

Looking down the last column provides insight into which groups stand to benefit the most from bequests. Bequests are larger for lower education groups for both blacks and whites. Black men with a high school education or less, and white men with less than a high school education have an expected discounted value of bequest that is much higher than the average for 
all men. This is driven primarily by high mortality rates among these groups. Bequests are smallest relative to the average for white college educated men, and for Hispanics. White college educated men have earnings that are $11 \%$ higher than average, but have a relatively low expected discounted value of bequests due to very low mortality rates. The Hispanic result is driven largely by the fact that their earnings are quite low, with an AIME ratio of only 0.714, and the fact that their mortality rates are lower than for other groups with similarly low earnings, such as low educated blacks. On the whole, it appears that allowing pre-retirement bequests is most beneficial to lower socioeconomic groups. This is because the mortality effect is, in most cases, more important than the relative income effect.

\section{The Payout Phase}

Assuming survival to retirement age, the individual then enters the payout phase, or decumulation phase, of the individual account. Perhaps the single most important design decision that must be made at this point is whether to require annuitization of the account balances at all. Then, assuming that some level of annuitization is required, there are many additional choices that must be made. How will the annuities be priced? Will the payout be fixed in real terms, nominal terms, or will it vary with some underlying portfolio? Will there be any provisions for bequests, such as guarantee periods or refund options? Will the annuity be written to cover one life or two? Will there be opportunities to take partial lump-sum withdrawals or to delay annuitization? Each of these choices has different implications for how different groups fare under the individual accounts system. Therefore, it is important to examine each of these issues separately. 


\subsection{To Annuitize or Not to Annuitize}

The first issue that must be addressed is whether or not the individual accounts system mandates annuitization. If individuals are allowed to freely access their account balances upon retirement, there would be no implicit transfers across groups, because at retirement, everyone would have access to their own contributions plus accumulated interest. This approach would make the individual account little more than a traditional savings vehicle, albeit a required one.

One problem with this approach of course is that it fails to provide individuals with any longevity insurance. As a result, individuals facing an uncertain date of death would find it difficult to allocate wealth in a manner that does not "waste" resources in the event of an early death without placing the individual at risk of outliving their resources. The insurance aspect of an annuity is potentially quite valuable. As shown by Brown, Mitchell and Poterba (1999), a 65 year-old male life cycle consumer with log utility and no bequest motive would find the opportunity to participate in an actuarially fair, real annuity market equivalent to a $50 \%$ increase in non-annuitized wealth. While this measure probably overstates the value of annuitization due to the omission of precautionary savings motives, bequest motives, and pricing loads, it is nonetheless an indication that the longevity insurance benefits of annuities are quite valuable. Most proposals to reform the existing Social Security system, which currently provides a real annuity to retirees, recognize that some form of annuitization is desirable for this reason.

Once it is recognized that some annuitization is desirable, there are many reasons to consider mandating a minimum level. These reasons include the possibility that myopic consumers may fail to provide adequately for old-age consumption, as well as the possibility of actuarially unfair pricing that arises due to adverse selection and/or the correlation between income and mortality. In what follows I proceed under the assumption that some level 
annuitization would be mandated in an individual accounts system, and focus on the implication of using different types of annuities. After reviewing the distributional implications of various annuity mandates, I consider whether partial or delayed annuitization can lessen the distributional impact.

\subsection{Pricing Assumptions}

The initial working assumption in this paper is that the entity that provides the annuity, be it the government or a private insurance firm, provides a "single price, zero profit" annuity to all individuals. "Single price" means that all individuals of the same age face the same price for a given stream of annuity income, i.e., annuity prices are not differentiated on the basis of individual or group characteristics. ${ }^{6}$ Prices would be permitted to vary based on the age of annuitization only. This assumption is made for two reasons. First, the existing OASI benefit formula does not differ along any gender, race, or educational guidelines. Two same-age individuals with the same average indexed monthly earnings (AIME) and who claim benefits on the same day, are entitled to identical monthly payments, regardless of any socioeconomic or demographic differences. Second, permitting such differences in the U.S., particularly along racial lines, would likely be politically infeasible if not illegal. While the private individual annuity market in the U.S. is permitted to use gender-specific pricing, job based pension annuities are not permitted to provide different annuity prices based on sex. ${ }^{7}$

The second assumption, that of "zero profit," simply means that the annuities are priced so that the system breaks even over the whole population. That is, the expected present

\footnotetext{
${ }^{6}$ Sheshinksi (1999) has demonstrated the conditions under which a uniform pricing scheme may be optimal.

${ }^{7}$ In the City of Los Angeles v. Manhart, 435 US 702 (1978), it was ruled that section 703(a)(1) of the Civil Rights Act of 1964 barred requiring women to contribute more than men to pensions to receive the same benefits. Five years later, Arizona Governing Committee v. Norris, 463 US 1073 (1983) held that the same law barred giving men a higher monthly benefit than women.
} 
discounted value of all future payouts is equal to the total of the premiums paid. The implicit assumption is that administrative costs of the program are zero. Another way of stating this is that the system is actuarially fair for the population as a whole, though not necessarily for any one individual. While this assumption is clearly inaccurate given the likely existence of some level of administrative costs, ${ }^{8}$ as long as these costs are apportioned as a fixed percentage of the account balance, this will reduce the money's worth ratio for everyone by the same amount. Therefore, the relative transfers that occur between groups would be unaffected.

\subsection{Measures of Distribution: The "Money's Worth" Ratio}

In order to evaluate the distributional consequences of a particular annuity structure, it is necessary to choose a metric. There are at least three measures of valuation that have been used in the literature on Social Security and annuities. These are: (i) a Money's Worth ratio, (ii) an internal rate of return, and (iii) a utility based measure of annuity valuation. Each of these measures provides a slightly different way of comparing annuity options.

The Money's Worth measure is defined as the expected present discounted value (EPDV) of the stream of annuity payments, divided by the premium paid. Take the simple case of an individual that pays an up-front, single-premium to purchase an immediate life annuity that pays \$A per month as long as the individual is alive. The money's worth, or MW, is defined as follows:

$$
M W=\frac{\sum_{j=1}^{T} \frac{A \cdot P_{j}}{(1+r)^{j}}}{\text { premium }}
$$

\footnotetext{
${ }^{8}$ Several chapters in Shoven (2000) explore the potential importance of administrative costs in an inividual accounts system. Samwick (1999) also provides an excellent discussion of reasons why these issues may be of less concern in the context of U.S. Social Security reform.
} 
where $P_{j}$ is the probability of living to period $j, r$ is the interest rate, and $T$ is the number of periods remaining to the end of the maximum possible life span.

The interpretation of the money's worth ratio is quite simple. If the MW is equal to one, then the expected discounted value of the benefit flow is exactly equal to the premium paid and can be said to be "actuarially fair" for the individual. If the MW is less than one, then the individual is expected to receive less back in payouts than he paid in the premium, and thus the system is placing a negative expected transfer, or expected tax, on this person. If the MW is greater than one, then the individual is expected to receive more in annuity payments than he or she paid into the system in premiums, and is therefore receiving a positive expected transfer.

The first thing to note about this set-up is that as long as mortality risk differs across groups, providing life annuities under a single price constraint will generally lead to the MW measure differing across individuals. That is, one can either have equal annuity payments per dollar premium for everyone, or one can have equal MWs for all individuals, but generally not both. ${ }^{9}$ Only by completely eliminating the role of mortality risk in the valuation of annuities can the differences in MW across groups be made to disappear.

The second method of measuring differences in annuity value is to use an internal rate of return, or IRR. This measure is really just a restatement of the MW measure, since the internal rate of return is, by definition, the value of $r$ that makes MW in equation 6 equal to one. Since the same information is contained in the MW measure and the IRR measure, little is gained by reporting both. Therefore, I will limit the results to the MW measure.

\footnotetext{
${ }^{9}$ While it is generally true that different survival curves lead to different epdv's of a given annuity flow, there are special cases in which two individuals with different survival curves will have an equal epdv. This requires a crossover in mortality rates, i.e., that one person have higher mortality at one age, and lower mortality at a different age. Similarly, it is possible that, with a non-zero discount rate, an individual with a longer life expectancy would none-the-less value an annuity less than an individual with a shorter life expectancy.
} 
Both the MW and the IRR measure are purely financial measures that do not capture the utility gains or losses associated with changes in a particular income stream. Risk averse individuals will value the longevity insurance provided by annuities. For example, Mitchell, Poterba, Warshawsky and Brown (1999) show that the utility gains to single life-cycle individuals are large enough that an annuity with a MW of only 0.80 might still be welfareenhancing.

In the context of measuring distributional impacts across demographic groups, however, a utility-based analysis is less appealing for several reasons. First, the magnitude of the utility gain is sensitive to the parameterization of the utility function and utility functions may differ across the demographic groups that we are analyzing. For example, there is some evidence that risk aversion may differ between men and women (Eisenhower \& Halek, 1999). A second difficulty is that many annuity options involve payments to the estate of an insured individual after death. In order to value these payments, it would be necessary to have a precise way to parameterize the utility of bequest function. There is remarkably little consensus in the literature about how to model bequest motives, and virtually no consensus about the particular parameterization. Research by Bernheim (1991), Laitner \& Juster (1996) and Wilhelm (1996) all point to the existence of operative bequest motives, while Hurd $(1987,1989)$ and Brown (1999a, 1999b) find little evidence in support of such a view.

For these reasons, I focus on the financial measure of Money's Worth, keeping in mind that the utility consequences of a particular policy may differ from the distribution of MWs. In particular, an individual may find an annuity welfare enhancing even if its MW is less than one. 


\subsection{Individual Annuities: Real and Nominal}

I first examine an annuity that closely mirrors the existing U.S. Social Security system an immediate real annuity written on a single life. With this form of an annuity, an individual simply exchanges their accumulated assets to the annuity provider (i.e., the government or the insurance company), and monthly payments to the individual commence immediately. The monthly payout is received until the individual dies, at which time the annuity contract ends. If the nominal payments from the annuity are indexed to the rate of inflation (as with the current OASI system), then the real value of the annuity payments is constant for the remainder of one's life.

The monthly income that would derive from an actuarially fair real annuity is easily computed. Assuming that an individual converts $\$ 100,000$ into such an annuity, the monthly annuity payment, A, to which the individual is entitled is found from the following equation:

$$
\$ 100,000=A \cdot \sum_{j=1}^{T} \frac{P_{j}}{(1+r)^{j}}
$$

where $r$ is the monthly real interest rate, $P_{j}$ is the cumulative probability of surviving from the date of purchase of the annuity to date $\mathrm{j}$, and $\mathrm{T}$ is the number of periods remaining until the individual reaches the assumed maximum life span. If the annuity were fixed in nominal dollars instead of being indexed to inflation, the monthly real interest rate $r$ would be replaced by the monthly nominal interest rate.

Due to the "single price" constraint, the value of A is constrained to be the same for all individuals. This is accomplished by constructing $\mathrm{P}_{\mathrm{j}}$ from a dollar-weighted average mortality of all participants in the individual accounts program. For purposes of this paper, the value of $\mathrm{A}$ is determined by using a unisex version of the 1978 birth cohort table from the 1995 Social Security Administration Trustees' report. This represents the "average" mortality of the entire 
population that turns age 22 in the year 2000, including men and women of all races and economic groups. Assuming a 3\% real interest rate, the value of A for a real single life annuity for a 67 year-old individual is $\$ 621.25$ per month.

It should be noted that this method of constructing the monthly payout of an annuity may differ from the value of $\mathrm{A}$ that would be required to make the system break-even. This is because the unisex table is weighted by the number of lives rather than the number of dollars in the accounts. It is not clear in which direction this may bias the value of $\mathrm{A}$, because there are two offsetting effects. First, a unisex table places heavy weight on female mortality, especially at older ages when the number of women in the population surpasses the number of men. If women, who have lower mortality rates, tend to accumulate lower account balances due to lower earnings and/or lower labor force participation, the use of a unisex table will understate average mortality. The second effects is that if individuals with larger account balances live longer, then using people-weights instead of dollar-weights will tend to overstate average mortality. Because these two effects work in offsetting directions, the net bias is unclear. Importantly, the effect of any such bias is to change the value of A for every one, so while the absolute level of the MW may change, the difference in MW across groups will remain unaffected.

To compute the MW for each gender/race/education group, the survival probabilities for that group are substituted into equation 6, so that:

$$
M W_{g}=\left\{\sum_{j=1}^{T} \frac{A \cdot P_{g, j}}{(1+r)^{j}}\right\} / 100,000
$$

Note that if $\mathrm{P}_{\mathrm{g}, \mathrm{j}}$ from equation 8 equals $\mathrm{P}_{\mathrm{j}}$ from equation 6 (i.e., group mortality equals the mortality rates used in pricing the annuity), then the annuity is priced in an actuarially fair manner for that group, and the MW will equal to one. 
Table 3 reports the MW values for the various demographic groups under three different assumptions. The first two columns report the MW for an individual real annuity when real rate of interest is $3 \%$ (column 1) and 6\% (column 2). Column 3 reports the MW for a nominal annuity when the real rate of interest and the rate of inflation are both set equal to a fixed $3 \%$. Note that a "nominal" annuity with a fixed inflation rate corresponds to a declining real annuity.

The first finding is that the use of a unisex pricing structure results in large expected transfers from men to women. Focusing first on the case of a real annuity with a $3 \%$ interest rate, we can see that because female mortality rates are lower than male mortality rates at all ages, the average MW for men is .920 while the average for women is 1.076 . This means that the average male can expect to receive 92 cents in annuity income for every dollar used to purchase the annuity, while the average woman can expect to receive nearly $\$ 1.08$ for every dollar contributed. In essence, this pricing structure results in approximately a transfer from men to women equal to approximately $8 \%$ of the accumulated wealth. Importantly, one way to "correct" for this transfer across genders, at least for the case of married individuals, is to require the purchase of a joint and survivor annuity, which will be discussed below.

Looking within gender groups, we also see large differences in the MW across racial/ethnic lines. Black men do particularly poorly under this individual real annuity, having a MW of only 0.862 . This means that the average black male can expect to lose approximately $14 \%$ of his account balance due to his higher mortality risk. White and Hispanic men, on the other hand, have quite slightly more favorable MW ratios of 0.927 and 0.920 due to their low mortality rates. A similar pattern is found among women, although in all cases the MW ratios are higher than for men. Black women on average have a MW close to one (1.022), indicating that the mortality advantage of being female is largely offset by the mortality disadvantage of 
being black. White women have a MW of 1.084, while Hispanic women have a very high MW of 1.123. Thus, just as black men are at a 14\% disadvantage, Hispanic women are at a $12 \%$ advantage when an individual real annuity is used.

Further segmenting the population by educational attainment shows even further diversity in the MW calculations. Across all racial and gender lines, there is a monotonic positive relationship between the level of education and the MW. Having at least a college education raises the MW to 0.967 for white men. It is also clear that low educated black males are the most disadvantaged group due to their poor mortality prospects. They can expect to receive only 80 cents on the dollar that is annuitized in a real annuity. The biggest "winners" are well-educated white women and Hispanic who have MW ratios of 1.106 and 1.123 respectively.

The next column in Table 3 shows how the results for a real annuity differ if the interest rate is $6 \%$ instead of $3 \%$. The central result is that a higher interest rate reduces the dispersion in MW ratios, raising the MW for groups with a low MW and lowering the MW for groups with a higher MW, although the reduction in dispersion is small. Increasing the interest rate from $3 \%$ to $6 \%$ increases the monthly payment from $\$ 621.25$ to $\$ 805.14$. In this case, individuals who die early will have already received a higher income in the early periods. Long-lived individuals also receive the higher benefit, and for longer, but these later payments are being discounted at a higher rate.

The third column of Table 3 reports the MW results for a nominal annuity. Nominal annuities may be less attractive than inflation indexed annuities, since the latter offer the advantage of providing a constant real consumption stream. Previous work by Brown, Mitchell \& Poterba (1999) indicates that real annuities offer utility gains in excess of that provided by annuities that are fixed in nominal terms, particularly in a world with uncertain inflation. 
However, the initial annuity payment is lower for real annuities. For example, if there were a constant inflation rate of $3 \%$ annually, the real annuity would have an initial payment of $\$ 621.25$ per month, while the nominal annuity would have an initial payment of $\$ 808.86$ per month. Due to inflation, however, the real value of the nominal annuity would decline over time at a rate of $3 \%$ per annum. Thus the real value of a nominal annuity is "front-loaded." For individuals facing higher than average mortality risk, front-loading annuities will increase their MW, since they are relatively more likely to be alive to receive these larger early payments.

Not surprisingly, the use of a nominal annuity has a similar effect as increasing the real interest rate, namely, it decreases the degree of dispersion in MW. This is simply because the shorter duration of the nominal annuity helps those with high mortality risk, and hurts those with low mortality risk. Using a nominal annuity in a world with a fixed inflation rate of $3 \%$ reduces the largest negative transfer (from low educated black men) to $17 \%$ of the account balance, versus $20 \%$ for a real annuity. It is again important to stress, however, that while providing a nominal annuity has the possibly beneficial effect of compressing the dispersion in MW ratios, it is possible that all groups could be made worse off by this choice. In a utility maximizing framework, the benefit of nominal annuities to high mortality risk individuals could be completely offset by the loss in utility from being subjected to an uncertain income stream.

It is important to recognize that the results so far may represent the "worst case scenario" from a distributional perspective. This is because the use of survivor and bequest options can improve the money's worth for individuals who value money left to beneficiaries. It is to these types of policies that I now turn. 


\subsection{Period Certain Options}

Continuing to operate within the realm of single life annuities, there are several options available that can help to increase the MW for individuals who face poor mortality prospects. A "Period Certain" option specifies a minimum number of years that the annuity payout will be made, regardless of the survival of the insured. Then, at the end of the guarantee period, the contract reverts to a straight life annuity and payments continue if and only if the insured individual is alive. In the current market for single premium immediate annuities in the U.S., insurance companies are willing to offer certainty periods of nearly any length, though 10 years and 20 years are most common.

With a "Period Certain" option, even if an individual faces a high probability of death early in the payout phase, the beneficiaries of the individual's estate will continue to benefit from the annuity. The reason these options serve to compress the distribution of MW ratios towards one is that they lessen the importance of individual mortality risk in the MW calculation.

Period certain options are quite common in private annuity markets in the U.S. According to the Life Insurance Market Research Association, if one looks at individuallypurchased (non-group) fixed individual annuities sold in the U.S., $73 \%$ of individual life annuities and $64 \%$ of joint and survivor life annuities included a period certain option (LIMRA 1998). TIAA-CREF also reports that $74 \%$ of male annuitants choose a period certain option on their annuity (King 1996). It is unclear what motivates this choice. Bequests are certainly one reason, since it is the beneficiaries of the policy that stand to gain from this policy. However, it seems unusual that an individual desire to leave a bequest only if they die in the next 10 years, but not thereafter. One natural alternative would be to leave a portion of wealth un-annuitized, and either gift it or bequeath it upon death. Discussions with individuals in the insurance 
industry indicate that the guarantee periods are often used more to overcome superstition or some form of ex ante regret that comes from the idea that one might turn over their money to an insurance company, and then die soon thereafter. A second alternative for leaving a bequest is for an individual to use a portion of the monthly annuity payment to pay the premium on a life insurance contract, thus offsetting a portion of any mandated annuitization (Bernheim, 1991). In previous work, however, I have shown that elderly individuals do not appear to use life insurance to offset the annuity from the existing Social Security system (Brown, 1999).

The pricing of a "life annuity with C year certain" is a straightforward extension of equation 7 above. Again assuming a $\$ 100,000$ initial premium, the annuity amount $A_{P C}$, is calculated as follows:

$$
\$ 100,000=A_{P C} \cdot\left\{\sum_{j=1}^{12^{*} C} \frac{1}{(1+r)^{j}}+\sum_{j=12^{*} C+1}^{T} \frac{P_{j}}{(1+r)^{j}}\right\}
$$

The difference from the formula for a straight life annuity is that for the first $\mathrm{C}$ years, payments are made regardless of the individual's survival. Therefore the $P_{j}$ term is excluded from the pricing equation for the first $12^{*} \mathrm{C}$ months.

Because the first $\mathrm{C}$ years of payments are not life contingent, the amount of the amount of the monthly payment $\mathrm{A}_{\mathrm{PC}}$ is less than the monthly income that would be received under a straight life annuity A. Table 4 shows the monthly income that would be available to an individual who chooses a single life annuity, a life annuity with 10 year certain and a life annuity with a 20 year certain. Looking at the first row, for real annuities, and again using the assumption of a unisex population average mortality table and a real interest rate of $3 \%$, we see that the monthly incomes for a 67 year-old annuitant are approximately $\$ 621, \$ 586$, and $\$ 503$ respectively. Thus, a 10 year period certain option reduces the income available to the insured 
by $6 \%$, while a 20 year option reduces monthly income by $19 \%$. For a nominal annuity, the nominal monthly incomes from these three options are approximately $\$ 809, \$ 760$, and $\$ 669$.

The fact that the survival probabilities for the first $\mathrm{C}$ years is irrelevant for the pricing of annuities with period certain options means that mortality differentials across individuals are also irrelevant during the first $\mathrm{C}$ years. As a result, period certain options offer an effective vehicle for bringing the money's worth ratios of various groups closer to one if an individual values benefits to survivors as much as benefits to himself. To think about the Money's Worth of a Period Certain product, let us generalize the MW formula as follows:

$$
M W=\frac{A_{P C} \cdot\left\{\sum_{j=1}^{12 * C} \frac{P_{j}+\left(1-P_{j}\right) \mu}{(1+r)^{j}}+\sum_{j=12 * C+1}^{T} \frac{P_{j}}{(1+r)^{j}}\right\}}{\$ 100,000}
$$

where $\mu$ represents a measure of the value of a dollar left to beneficiaries to the value of a dollar consumed by the individual purchasing the annuity. If $\mu=1$, we are back to purely a financial calculation, and assuming that a dollar to the insured individual's estate is equivalent to a dollar to the individual while alive. In this case, the individual fully values the first $\mathrm{C}$ years of payments, regardless of survival. If $\mu<1$, then the individual values a dollar to his estate less than a dollar while alive. In the extreme case of $\mu=0$, the individual does not value the period certain benefits at all, and the formula collapses to equation 9. Only now, because $\mathrm{A}_{\mathrm{PC}}$ is less than A when there is no period certain benefit, the MW will be much lower.

Table 5 reports results for real annuities with period certain options, for the case of $r=.03$. The first column reports the MW for the real individual life annuity first reported in table 3. Columns 2 and 3 report the MW for a real annuity with a 10 year period certain feature, under two different assumptions about $\mu$ ( 1 and 0$)$. Columns 4 and 5 report results for a real annuity with a 20 year period certain feature, again for two values of $\mu$. 
Comparing columns 1 and 2, we see that if individuals fully value income to beneficiaries $(\mu=1)$, then the use of a 10-year period certain option reduces dispersion by pushing most of the MW measures towards one. The overall effect is modest, increasing the average male MW from 0.920 to 0.936 and decreasing the average female MW from 1.076 to 1.061 . Usually, however, the more a group's mortality differs from that of the average, the greater the change in the MW as we move from straight life to period certain annuities. Considering the effect on the "outliers," we see that the MW for low educated black males increase by roughly $6 \%$ of wealth, from 0.800 to 0.861 , and that for highly educated white women decreases from 1.106 to 1.080.

Columns 3 , however, shows that this reduction in the MW dispersion is clearly dependent on the assumption that $\mu=1$. If $\mu=0$, so that individuals place no value on money left behind in an estate, the MW falls below the level of a real annuity for everyone, and the level of dispersion is similar to the level in column 1. For example, the difference between the highest MW (Hispanic women) and the lowest MW (black men less than high school) is .323 for a life annuity and .306 for an annuity with a 10 -year period certain option that has no value $(\mu=0)$.

The final two columns of table 5 show results for the case of a 20 -year period certain option. The effect on the MW of a 20 year PC option is substantially greater than that of a 10 year, because mortality is rising rapidly between ages 77 and 87 (the second 10-year period for an individual annuitizing at age 67). Assuming that survivor benefits are valued fully, all of the MWs are now much closer to one. The largest negative transfer is now less than less than 5\%, down from $20 \%$ with a straight life annuity. Thus, to the extent that annuitants fully value benefits to their beneficiaries, a 20 -year period certain option substantially reduces the degree of redistribution. Once again, however, if benefits paid to beneficiaries are not fully valued, individuals can be made substantially worse off. In fact, with $\mu=0$, every single Money's Worth 
ratio is less than one. Even college educated white women have a MW of below 0.90. The reason is simple - a 20 year period certain option reduces monthly income by $19 \%$. This $19 \%$ is a pure cost if the individual does not place any value on the benefits paid after death.

\subsection{Refund Options}

Annuity providers often provide "refund" options to annuitants as an alternative to a period certain feature. While there are many possible ways to structure a refund option, the most popular form in the U.S. market for immediate annuities is to offer a "money back guarantee." The annuity company offers to provide a monthly payment $\mathrm{A}_{\mathrm{r}}$ for as long as the individual lives. Upon death, the company agrees to return to the beneficiary the initial premium, minus any annuity payments made to date. For example, suppose an individual purchases an annuity with a $\$ 100,000$ premium, and receives $\$ 500$ per month in income from a refund annuity. After 10 years (120 months), the individual will have received $\$ 60,000$ in (nominal) payments. If the insured dies at this point, his beneficiaries would receive $\$ 40,000$. Note that the amount guaranteed is the nominal value of the original premium, and no consideration is given to issues of discounting.

A second popular refund option works in a similar manner. The difference is that instead of providing a lump-sum "payoff" at death, it continues to provide monthly payments $A_{r}$ to the beneficiary until such time that the nominal value of the premium has been paid out. In this case, the annuity is little more than a $\mathrm{C}$-year period certain product in disguise, where the guarantee period $\mathrm{C}$ is chosen so that $\mathrm{A}_{\mathrm{r}} *(12 * \mathrm{C})=$ Premium. For example, with an interest rate of $3 \%$ and an inflation rate of $3 \%$, an annuity an installment refund annuity sold to a 67 year old is identical to a "life annuity with 11.4 year period certain." Calculations of the Money's Worth ratios for 
both of these options indicate that they lie between the rates for a straight life annuity, and a life annuity with a 20 year period certain option, and so are not reported separately in the tables.

In theory, one could provide a refund option that ensures that the beneficiaries receive a death benefit that returns the full actuarial value of the annuity upon the death of the beneficiary. In fact, such a "residual balance annuity" is discussed in Feldstein \& Ranguelova (1999) for the case of a variable annuity product. In the case of a fixed annuity, this would result by definition in a MW equal to one for everyone. However, this product offers no mortality premium, and in fact, no insurance market is even required. Individuals can replicate this residual balance annuity by amortizing the account balance in real terms over the maximum remaining years of life. For perspective, while a real annuity with no period certain offers a real monthly payment of $\$ 621$, amortizing the $\$ 100,000$ until age 100 results in a monthly income of only $\$ 389$, a $37 \%$ reduction. In addition, this approach requires that the individual know the maximum possible age with certainty. If there is any chance that the individual would live past age 100, she would outlive her resources.

\subsection{Joint and Survivor Annuities}

According to the Census Bureau projections for the year 2000, 62.4\% of individuals aged 65 to 74 will be married with a spouse present. Married individuals nearing retirement are concerned with the consumption opportunities of both spouses, and therefore a single life annuity may be inappropriate. Joint and survivor annuities, which provide a stream of income as long as either spouse is alive, provide a spouse with protection against a drop in living standard upon the death of the insured individual.

Another reason for considering joint life annuities is that it provides a mechanism for providing for non-working spouses of insured individuals. While the labor force participation of 
women has been steadily increasing throughout the $20^{\text {th }}$ century, it is likely to continue to be the case that large numbers of married individuals (primarily women) will accumulate very little in an individual account. Mandating the use of joint and survivor annuities for married couples is one way to ensure some level of income for elderly widows.

As discussed in more detail in Brown \& Poterba (1999), there are two primary types of joint annuity contracts. The first is a joint life annuity with a last survivor payout rule. This rule specifies a monthly payment that will be paid as long as both members of the couple are still alive, and also specifies a fraction of this payment, $\phi$, that will be paid to the survivor after the death of one member of the couple. With the second type of contract, often called a joint and contingent survivor annuity, one member of the couple is specified as the primary annuitant. As long as the primary annuitant is alive, the annuity payment is fixed at A. However, upon the death of the primary annuitant, the payment to the secondary annuitant declines to a fraction $\theta$ of the original payment. If, on the other hand, the secondary annuitant dies first, the payment to the primary annuitant does not change.

This paper will restrict attention to joint and last survivor annuities, which treats the spouses symmetrically. The pricing of a joint and survivor annuity is again a simple extension of the pricing of a single life annuity.

$$
\$ 100,000=A_{J \& S} \sum_{j=1}^{T} \frac{\left\{P_{m, j} \cdot P_{f, j}+\phi \cdot\left(P_{m, j} \cdot\left(1-P_{f, j}\right)+P_{f, j} \cdot\left(1-P_{m, j}\right)\right)\right\}}{(1+r)^{j}}
$$

In pension plans and in the individual annuity market, $\phi$ is usually set equal to $0.5,0.67$, or 1.0, although insurance companies are generally willing to provide annuities for any value of $\phi$ between 0 and 1 . When $\phi$ takes the value of 1.0, these products are often called "joint and full survivor" annuities. In this case, the monthly annuity payment does not change upon the death 
of the first spouse. In order to compute the value of $A_{J \& S}$ above, one must decide which values of $\mathrm{P}_{\mathrm{m}, \mathrm{j}}$ and $\mathrm{P}_{\mathrm{f} . \mathrm{j}}$ to use for pricing the annuity. Rather than using a unisex table, in this case $\mathrm{I}$ choose to use average male mortality rates to compute $\mathrm{P}_{\mathrm{m}, \mathrm{j}}$ and average female mortality rates to compute $\mathrm{P}_{\mathrm{f}, \mathrm{j}} \cdot 10$

To compute the Money's Worth for different groups, it is now necessary to match up characteristics of husbands and wives. With 7 different racial/ethnic/education groups for each gender, this leads to 49 different possible "couples." Rather than examine every combination, results are presented for the case in which matching occurs within groups. Therefore, white college educated men are matched with white college educated women. Table 6 reports results for real annuities, both for a 50\% survivor benefit (top panel) as well as for a full survivor benefit (lower panel). In the first column I report results for a joint and survivor annuity with no period certain option. In columns 2-5, I report the MW for joint and survivor annuities with 10 and 20 year period certain options. In each of the period certain cases, I show results for $\mu=1$ (full valuation of beneficiary income) and $\mu=0$ (zero valuation).

As the results indicate, the MW ratios are substantially closer to one than in the case of individual annuities. For example, even in the case of the lowest money's worth for a full survivor annuity, that of low educated blacks, the MW for a joint and full survivor annuity is 0.932. The highest couple MW is 1.021 for Hispanic couples. While these implicit transfers are still large in magnitude, they are much smaller than for individuals alone for two reasons. First, even if two individuals with identical mortality purchase a joint-and-survivor annuity, the MW will be closer to 1.0. This is because the annuity will continue to pay out as long as either of the

\footnotetext{
${ }^{10} \mathrm{I}$ have also calculated the MW ratios for joint and survivor annuities under the assumption that it is priced using the unisex table for both spouses. The results are nearly identical, with the MW calculated under these two methods never varying by more than .003 .
} 
two individuals is alive, and the probability that both individuals die very early is less than the probability that any one of them will. For example, even if two individuals with the mortality characteristics of low-educated black males were to purchase a joint and full survivor annuity, the MW would be 0.843 , as opposed to a MW of 0.800 if each individual purchased a separate single life annuity. The second reason, which has an even greater effect on the results, is that one of the primary sources of variation in mortality rates is gender. By pooling together the mortality of a male and a female, and pricing accordingly, this source of dispersion in the money's worth ratio is largely removed. Thus, even in the case of a couple consisting of a black male and a black female, both with less than a high school education, the MW ratio is 0.932 . The lower panel of table 6 shows similar results for the case of a joint and 50\% survivor annuity. Comparing the upper and lower panels, we see that higher survivor benefits tend to reduce MW dispersion by more.

The remaining columns in Table 6 report results of combining a real joint and survivor annuity with a year period certain option. As with the case of individuals, the inclusion of a period certain option tends to decrease the dispersion of MW ratios if the benefits to beneficiaries are fully valued. In the case of a joint and full survivor annuity with a 20 year period certain, the MW ratios are extremely close to one. The largest negative transfer appears to be from low educated blacks, but it represents only a $2.1 \%$ reduction in wealth. The largest positive transfer is to Hispanic couples, who receive a net surplus of $1.2 \%$.

It must again be noted, however, that providing a joint and survivor annuity with a 20 year period certain option has a cost. This cost is a decline in the monthly income that is made available to individuals when they annuitize. For example, whereas a real single life annuity provided $\$ 623$ per month in income, a joint and full survivor annuity provides only $\$ 503$ in 
income. Adding a 20-year certain option to this annuity reduces the benefit further to $\$ 474$ per

month. As a result of this nearly $6 \%$ reduction in income from adding a $20 \%$ period certain to a joint and survivor annuity, the MW of the 20-year period certain is significantly lower if the couple does not value income to beneficiaries (i.e., if $\mu=0$ ).

\subsection{Variable Annuity Issues}

Up until this point, the annuities discussed in this paper have been fixed nominal or fixed real annuities. The defining feature of these annuities is that once the initial value of the annuity is determined, it remains constant in nominal or real terms for the duration of the annuity contract (excepting pre-determined reductions upon one death in a joint and survivor annuity). However, many proposals for an individual accounts system, such as that outlined by Feldstein, Ranguelova, and Samwick (1999), foresee a role for variable annuity products.

The general conclusions of the distributional analysis conducted for fixed annuities carries over for variable annuity products as well. With variable products, it will still be the case that, in expectation, resources are transferred from high-mortality risk individuals to lowmortality risk individuals. It also remains true that the use of joint life annuities, period certain guarantees, and refunds reduce the extent of these transfers. However, there is one additional "choice variable" in constructing a variable annuity payout stream that deserves attention here the "Assumed Interest Rate," or AIR.

As discussed in Bodie \& Pesando (1983) and Brown, Mitchell \& Poterba (1999), the amount of the initial variable annuity payment is a function of the AIR. To determine the initial value $\mathrm{A}(0)$ of a single life variable annuity, the insurance company solves an equation like:

$$
1=\sum_{j=1}^{T} \frac{A(0) \cdot P_{j}}{(1+R)^{j}}
$$


where $\mathrm{R}$ is the AIR. The annuity updating rule depends on the return of the assets that back the annuity, which is denoted by $\mathrm{z}_{\mathrm{t}}$, according to:

$$
A(t+1)=A(t) \cdot \frac{\left(1+z_{t}\right)}{(1+R)}
$$

$\mathrm{R}$ is the key parameter in designing a variable annuity. Assuming a high value of $\mathrm{R}$ will enable the insurance company to offer a large initial premium, but the stream of future payouts is less likely to increase, or more likely to decline, as the assumed value of $\mathrm{R}$ rises.

For example, if $\mathrm{R}$ is set equal to the expected real return on the underlying portfolio, then the expected slope of the real consumption stream is flat. That is, if the portfolio return in each period was equal to its expectation, and thus equal to $\mathrm{R}$, the real value of the annuity would be constant in real terms. In periods when the portfolio's real return falls short of its expectation, the real value of the annuity payment would fall. Similarly, when the portfolio outperforms expectations, the annuity value would rise in real terms. If $\mathrm{R}$ is set equal to 0 , the initial value of the annuity, $A(0)$ is relatively low, but the income stream will rise and fall in exact proportion to the underlying portfolio. Therefore, the annuity payments will, on average, increase in value at a rate equal to the expected return of the underlying portfolio.

As was the case with fixed annuities, "front-loading" annuities has the effect of lessening the size of the expected transfers, since high-mortality risk individuals are more likely to receive a higher proportion of their premium back. Thus, setting a higher assumed interest rate will result in less redistribution from high mortality rate groups to lower mortality groups. This finding is directly analogous to the difference between real and nominal annuities discussed earlier - high mortality risk individuals receive a higher money's worth out of nominal annuities because the real value of these payments are higher in the early periods. 


\subsection{Delayed Annuitization}

As reported by Finkelstein \& Poterba (1995), pensions in the United Kingdom since 1995 have offered an "income withdrawal option." This option allows an individual to delay the purchase of an annuity until age 75 , provided that he or she draws an income from the pension fund in the meantime that is between 35 and $100 \%$ of the amount that would otherwise be received from an annuity. If the pensioner dies prior to annuitization, the assets in the fund become part of the individual's estate.

From an expected bequest point-of-view, this option benefits the estate of individuals who have particularly high probabilities of dying between the ages of 67 and 77 . Table 7 reports the 10 -year mortality probability of each group, conditional on reaching age 67 . As the table indicates, large disparities in mortality rates continue at these older ages. Female mortality rates are still below those of men, blacks have higher mortality rates than whites and Hispanics, and lower education groups have higher rates than high education groups.

As with all bequest options, the difficulty with this approach it must reduce the income available to annuitants. I have already shown that a 67 year-old individual purchasing an annuity with $\$ 100,000$ would be entitled to a monthly income of $\$ 621$, assuming that annuities were priced on a unisex basis. Imagine that instead of purchasing an annuity at age 67 , the individual instead consumed $\$ 621$ per month out of the individual account, and that the account continued to accrue interest at a rate of $3 \%$ per annum. After 10 years, the individual would have an account balance of $\$ 47,759$. If the individual annuitizes the account balance at this point, the annuity would provide monthly income of approximately $\$ 419$, or fully one-third less than the income that would have been provided if an annuity were purchased ten years earlier. This is the 
fundamental trade-off - if the individual dies between ages 67 and 77, the heirs receive at least $\$ 47,759$ dollars. But if the individual survives, her income is $33 \%$ less for the rest of her life.

Alternatively, consider what would happen if the individual did not annuitize at all, but continued to consume $\$ 621$ per month starting at age 67 . The individual account would be depleted after 17 years and 2 months, or at age 84 . Approximately $44 \%$ of all men and $61 \%$ of all women will still be alive at age 84 , the point at which they would exhaust their resources if they tried to "self-annuitize." This is quite obviously not the optimal consumption path in the absence of annuitization, but it illustrates the key point that delaying annuitization comes at a cost of future consumption for longer-lived individuals.

\subsection{Partial Annuitization Revisited}

Now that we have discussed numerous annuity payout options in more detail, it is instructive to again revisit the issue of partial annuitization. All of the transfers noted above occur as a result of mortality differentials across groups. Any portion of an account that is not annuitized is therefore not subject to these redistributive effects. Put simply, if individuals are required to annuitize exactly 50\% of their account balances, then the amount of redistribution would be cut in half, since the "money's worth" of the non-annuitized portion is equal to 1.0 .

One possible partial annuitization policy would be to require a minimum amount of annuitization, where the minimum was chosen to be above some baseline level, such as the poverty line. In the U.S., it would be important to set the baseline above the level of any other government income guarantee program, such as SSI, in order to ensure that individuals did not rapidly spend down their individual account assets and then become dependent on SSI.

The primary disadvantage of allowing for partial lump-sum withdrawals is that individuals lose part of the longevity insurance that an annuity is meant to provide. The 
individual is still faced with the problem of determining how to optimally allocate the nonannuitized wealth in the face of an uncertain lifetime. If one of the reasons for requiring a forced retirement savings program at all is that individuals are too myopic to save adequately for old age, then this myopia may lead them to squander the lump-sum portion of their savings in a suboptimal fashion.

Despite these disadvantages, allowing for some fraction of benefits to be left unannuitized has several potential benefits. First, as we have seen, it reduces the amount of redistribution in the annuity pricing system from long-lived to short-lived individuals. Second, it loosens the liquidity constraint on the elderly that an annuity imposes, which can be beneficial in cases in which the elderly are hit with large unplanned expenditures, such as for unforeseen medical expenditures. Third, it provides individuals with bequest motives a natural way to provide gifts and/or bequests to their children, that is not subject to the somewhat arbitrary timing constraints of the bequest that comes with period certain or refund options on an annuity. Finally, it should be noted that the utility gains that come from annuitizing one's resources are a decreasing function of the amount of wealth already annuitized. In other words, the first dollar of annuitized wealth has a much larger utility impact than the last dollar. Therefore, annuitizing $50 \%$ of one's wealth captures significantly more than $50 \%$ of the utility gains from annuitization. Thus, the "cost" of the lump-sum option may not be as great as it seems at first glance.

The U.K. retirement system has a "partial annuitization" option in its personal pension schemes, as described in Finkelstein \& Poterba (1999). In these personal pension plans, individuals are permitted to take up to $25 \%$ of their fund (up to a maximum amount) as a lumpsum at retirement. It is important that this lump-sum option is an option, not a requirement, of the program. Allowing this as an option rather than as a requirement has two partially offsetting 
effects from a distributional perspective. If it is primarily lower socioeconomic groups (with higher mortality rates) that choose the lump-sum option, this places more resources into their hands prior to death, presumably making them better off. However, this selection process will also have the effect of making annuities more expensive, since the dollar-weighted mortality rates of the annuitized pool would be improved. This would reduce reduce the money's worth of annuities to all participants, including those in the least well of groups.

\section{Alternative Pricing Assumptions}

Nearly all of the numerical results of the last section were driven entirely be the "single price" assumption, i.e., the constraint that all individuals of the same age would receive the same monthly annuity income per dollar of premium paid, regardless of individual characteristics. This assumption is certainly not the only assumption that can be made, although it is arguably the most politically feasible. For example, private annuity markets in the U.S. currently price annuities separately for men and women. In addition, there is at least one U.S. company that offers a "Smoker's Preferred" annuity contract, that offers higher monthly income for individuals who are smokers, and thus have higher mortality risk.

It is in the interest of individuals who face high mortality risk to allow the annuity provider to use as much information as possible to price annuities. The reason is that a provider can offer a much higher level of monthly income to a high mortality risk individual if they are allowed to price based on this higher risk level. This leads to some results that are quite counter to our usual sense of political feasibility. For example, it would be very much in the interest of black men with less than a high school education to allow insurance companies to use race as a factor in the pricing of annuities. 
For perspective, table 8 reports the monthly annuity payment that would be offered to individuals if annuity prices were set separately for each demographic group, and were priced in an actuarially fair manner for each group. Recall that when individual real annuities were priced based on a single unisex life table with a real interest rate of $3 \%$, a $\$ 100,000$ premium bought an individual a stream of payments of approximately $\$ 621$ per month for a 67 year-old. Allowing for gender specific pricing only, men would receive \$675 per month, while women would receive $\$ 577$ per month.

Allowing pricing based on gender and race would result in white, black, and Hispanic men receiving $\$ 670, \$ 720$, and $\$ 675$ per month respectively. White, black, and Hispanic women would receive $\$ 573, \$ 608$, and $\$ 553$ respectively. Further differentiation by educational status results in an even wider dispersion of monthly payments. Again looking at the extreme cases, a low educated black male would receive $\$ 777$ per month, fully $\$ 215$ more per month than a white, college educated woman.

It is also important to note however that "group" mortality rates are only averages, and that there is a significant degree of dispersion around this average within each group. Thus, while it is true that college educated white women on average live longer than black men with less than a high school education, it is not true that this holds for every individual in each group. Some white women will have mortality rates that more closely resemble that of black men, and vice-versa. As a result, any pricing scheme that seeks to address mortality heterogeneity by pricing based on group characteristics will make some individuals even worse off. For example, if annuities are priced on a gender-specific basis, this will be especially harmful to women who have mortality rates that look more like those of men. Of course, it is now conceivable to think that, given the rapid rise in medical technology, companies in the future will be able to determine 
individual-specific mortality rates with a fairly high degree of precision. Already, there is debate about whether to allow insurance companies to use data from DNA tests to make insurance decisions. Unlike markets for health insurance and life insurance, in which unhealthy individuals would prefer that the insurance company not be permitted to use this information, in annuity markets the preferences are reversed. Individuals who can be identified as being at a higher risk of dying should welcome the use of this information in the pricing of annuities, as it would lead to a higher benefit.

\section{Summary and Future Directions}

This paper has measured the magnitude of the expected transfers that would result under various annuity options in an individual accounts system. These expected transfers arise because mortality is significantly correlated with socioeconomic factors such as gender, race, and level of education. These transfers appear to be economically important in both the accumulation phase of the individual accounts and in the payout phase.

Allowing for pre-retirement bequests from individual accounts is relatively more important to groups with high mortality rates at younger ages. For example, estimates from this paper suggest that $41.2 \%$ of 22 year old black males with less than a high school education in the year 2000 will not survive to age 67 . While these high mortality rate groups tend to have below average lifetime earnings, the net effect appears to be that these low-income groups tend to have higher expected bequests than higher income groups. Thus, allowing pre-retirement bequests may be an important element in reducing the extent of regressive redistribution.

During the payout phase of the annuity, mortality differences are also quite important. Assuming that the political system constrains annuity prices to be blind to socioeconomic 
mortality differences, the "money's worth" of retirement annuities can vary greatly across groups. The money's worth is lower for men than for women, lower for blacks than for whites, and are increasing in an individual's education level. For some annuity design options, such as an individual, real life annuity, these transfers can be as large as $20 \%$ of wealth. Importantly, these expected transfers are generally regressive, in the sense that they are going from the economically worse off individuals to better off individuals.

The degree of dispersion in the money's worth ratios is very sensitive to the precise structure of the annuity program. Annuities which "front-load" payments, or which provide continued payments to an individual's estate after death, result in much less redistribution. The use of joint life annuities rather than single life annuities largely eliminates the transfers that occur across gender lines. The use of a joint and survivor annuity with a "20-year certain" provision reduces the largest negative transfer to only $2 \%$ of wealth.

All of the options that reduce the implicit transfers do so at the cost of lowering the monthly income that can be provided to all annuitants. For example, moving from a real single life annuity with no bequest provision to a real joint and full survivor annuity with a 20-year period certain would reduce the monthly income from the annuity by nearly $24 \%$. If a goal of an individual accounts system is to ensure a level of monthly income that is no lower than would be available under the current OASI system, as suggested by Feldstein et al (1999), the use of a joint-and-full-survivor annuity with a 20 year certain option would require a $24 \%$ increase in the annual contribution rate over the rate required with a single life annuity.

All of these results are based upon purely financial considerations, such as the expected present value of payments received. These measures do not capture the utility gains associated with the longevity insurance component of annuities, which life cycle simulations indicate may 
be quite substantial. In order to embed the distributional analysis into a utility framework, additional work is needed in at least two areas. First, further research is needed into the differences, if any, in utility parameters such as risk aversion across demographic groups.

Second, additional work is required to adequately parameterize the utility of bequest function.

Both of these issues are largely unresolved in the existing literature. Another avenue for future research is in better understanding the underlying determinants of the large mortality differentials that we observe across racial, gender, and economic lines. 


\section{REFERENCES}

Attanasio, O.P. \& H.W. Hoynes, "Differential Mortality and Wealth Accumulation," NBER Working Paper No. 5126, 1995.

Bernheim, B.D., "How Strong are Bequest Motives? Evidence Based on Estimates of the Demand for Life Insurance and Annuities," Journal of Political Economy, Vol. 99, 1991.

Bodie, Z. \& J. Pesando, "Retirement Annuity Design in an Inflationary Climate," in Z. Bodie \& J. Shoven, Eds., Financial Aspects of the U.S. Pension System, Chicago: University of Chicago Press, 1983.

Brown, J.R., "Private Pensions, Mortality Risk, and the Decision to Annuitize," NBER Working Paper No. 7191, 1999 (a).

Brown, J.R., "Are the Elderly Really Over-Annuitized? New Evidence on Life Insurance and Bequests," NBER Working Paper No. 7193 (b).

Brown, J.R. \& J.M. Poterba, “Joint Life Annuities and Annuity Demand by Married Couples,” NBER Working Paper No. 7199, 1999.

Brown, J.R., O.S. Mitchell, \& J.M. Poterba, "The Role of Indexed Bonds and Real Annuities in an Individual Accounts Retirement Program,” NBER Working Paper No. 7005 and forthcoming in J. Campbell \& M. Feldstein, eds., Risk Aspects of Social Security Reform, 1999.

Deaton, A. \& C. Paxson, "Mortality, Education, Income and Inequality Among American Cohorts," NBER Working Paper No. 7140, 1999.

Duggan, J.E., R. Gillingham, \& J.S. Greenlees, "Progressive Returns to Social Security? An Answer from Social Security Records," Research Paper No. 9501, U.S. Department of the Treasury, 1995.

Eisenhower, J.G. and M. Halek, "The Demography of Risk Aversion,” working paper presented at annual meeting of the American Risk and Insurance Association, Aug. 1999.

Feinstein. J.S., "The Relationship Between Socioeconomic Status and Health: A Review of the Literature,” The Milbank Quarterly, Vol. 71, No. 2, 1993.

Feldstein, M. \& J. Liebman, “The Distributional Effects of an Investment-Based Social Security System,” NBER Working Paper No. 7492, 2000, and forthcoming in M. Feldstein and J. Liebman, eds., Distributional Aspects of Social Security and Social Security Reform.

Feldstein, M. \& E. Ranguelova, “The Economics of Bequests in Pensions and Social Security,” NBER Working Paper No. 7065, 1999.

Feldstein, M, E. Ranguelova, \& A. Samwick, "The Transition to Investment-Based Social Security when Portfolio Returns and Capital Profitability are Uncertain,” NBER Working Paper \# 7016, 1999.

Finkelstein, A. \& J.M. Poterba, "Selection Effects in the Market for Individual Annuities: New Evidence from the United Kingdom,” NBER Working Paper \# 7168, 1999.

Garrett, D.M., "The Effects of Differential Mortality Rates on the Progressivity of Social Security,” Economic Inquiry, Vol. 33, July 1995.

Hadley, J. \& A. Osei, "Does Income Affect Mortality? An Analysis of the Effects of Different Types of Income on Age/Sex/Race-Specific Mortality Rates in the United States," Medical Care, Vol. 20, No. 9, 1982.

Hurd, M.D., "Mortality Risk and Bequests," Econometrica, Vol. 57, No. 4, 1989.

Hurd, M.D., "Savings of the Elderly and Desired Bequests," American Economic Review, Vol. 77, No. 3, 1987.

Jordan, C.W., Life Contingencies, $2^{\text {nd }}$ edition, Chicago, IL: Society of Actuaries, 1991.

Kaplan, G.A., E.R. Pamuk, J.W. Lynch, R.D. Cohen, and J.L. Balfour, "Inequality in Income and Mortality in the United States: Analysis of Mortality and Potential Pathways," BMJ, Vol. 312, April 1996. 
King, F., "Trends in the Selection of TIAA-CREF Life Annuity Income Options, 1978-1994," TIAA-CREF Research Dialogues, Issue 48, 1996.

Kitagawa, E.M. \& P.M. Hauser, Differential Mortality in the United States: A Study in Socioeconomic Epidemiology, Harvard University Press, 1973.

Kotlikoff, L. and J. Sachs, "The Personal Security System: A Framework for Reforming Social Security,” Federal Reserve Bank of St. Louis Review, Vol. 80 (2), March-April 1998.

Laitner, J. and T. Juster, "New Evidence on Altruism: A Study of TIAA-CREF Retirees," American Economic Review, Vol. 86, 1996.

Lantz, P.M., J.S. House, J.M. Lepkowski, D.R. Williams, R.P. Mero, J.Chen, "Socioeconomic Factors, Health Behaviors, and Mortality," Journal of the American Medical Association, Vol. 279, No. 21, June 1998.

Liebman, J., "Redistribution in the Current U.S. Social Security System," this volume, 1999.

Lillard, L.A., M.J. Brien, and C.W.A. Panis, "The Value of Annuities at Age 65: Race, Marital Status, Wealth, Health, and Mortality," Rand Corportation mimeo, 1993.

LIMRA International, "Product Design Series: Immediate Annuities," Hartford, CT, 1998.

Menchik, P.L., "Economic Status as a Determinant of Mortality Among Black and White Older Men: Does Poverty Kill?" Population Studies, Vol. 47, 1993.

Mitchell, O.S., J.M. Poterba, M.J. Warshawsky, and J.R. Brown, "New Evidence on the Money's Worth of Individual Annuities," American Economic Review, forthcoming 1999.

Pablos-Mendez, A., "To the Editor," Journal of the American Medical Association, Vol. 271, No. 16, April 27, 1994.

Palmer, B.L., "Implications of the Changing Male Mortality,” M.I.T. Ph.D. Dissertation, 1989.

Panis, C., \& L. Lillard, "Socioeconomic Differentials in the Returns to Social Security," RAND Corporation mimeo, February 1996.

Preston, S.H., I.T. Elo, I. Rosenwaike, \& M. Hill, “African-American Mortality at Older Ages: Results of a Matching Study,” Demography, Vol. 33, No. 2, May 1996.

Samwick, A., "Social Security Reform in the United States," National Tax Journal, Vol. LII, No. 4, December 1999.

Sheshinksi, E., “A Note on the Optimum Pricing of Annuities," unpublished manuscript, 1999.

Shoven, J., Administrative Costs and Social Security Privatization, University of Chicago Press, 2000.

Smith, J.P., "Healthy Bodies and Thick Wallets: The Dual Relation between Health and Economic Status," Journal of Economic Perspectives, Vol. 13 (2), p 145-66, Spring 1999.

Sorlie, P., E. Backlund, N. Johnson, and E. Rogot, "Mortality by Hispanic Status in the United States," Journal of the American Medical Association, Vo. 270, No. 20, Nov. 24, 1993.

Sorlie, P., E. Rogot, R. Anderson, N.J. Johnson, and E. Backlund, "Black-White Mortality Differences by Family Income," The Lancet, Vol. 340, August 1992.

Wilhelm, M., "Bequest Behavior and the Effect of Heirs' Earnings: Testing the Altruistic Model of Bequests," American Economic Review, vol. 86, 1996. 
TABLE 1

Conditional Life Expectancy by Gender, Race, Hispanic Status, and Education

\begin{tabular}{|c|c|c|c|c|}
\hline & \multicolumn{2}{|c|}{$\begin{array}{c}\text { Conditional Life Expectancy } \\
\text { at age } 22\end{array}$} & \multicolumn{2}{|c|}{$\begin{array}{c}\text { Conditional Life Expectancy } \\
\text { at age } 67\end{array}$} \\
\hline & Men & Women & Men & Women \\
\hline All & 77.4 & 83.4 & 83.5 & 87.2 \\
\hline All Whites & 78.3 & 84.0 & 83.6 & 87.4 \\
\hline All Blacks & 71.8 & 80.0 & 82.3 & 86.1 \\
\hline All Hispanics & 77.4 & 85.2 & 83.5 & 88.3 \\
\hline Whites: College + & 80.5 & 85.1 & 84.4 & 87.8 \\
\hline Whites: HS + & 77.8 & 83.9 & 83.4 & 87.3 \\
\hline Whites: < HS & 75.3 & 82.1 & 82.3 & 86.5 \\
\hline Blacks: College + & 75.7 & 81.9 & 83.4 & 86.8 \\
\hline Blacks: HS + & 71.6 & 80.0 & 82.2 & 86.1 \\
\hline Blacks: < HS & 68.1 & 77.5 & 81.0 & 85.1 \\
\hline
\end{tabular}

Notes: "Conditional Life Expectancy" is used to describe the age to which an individual can expect to live, conditional on attaining age 22 or 67.

Source: Author's calculations as described in text. 
TABLE 2

Expected Bequests by Gender, Race, Hispanic Status and Education (Men Only)

\begin{tabular}{|c|c|c|c|c|c|c|c|c|}
\hline & \multirow{2}{*}{$\begin{array}{c}\text { Ratio of } \\
\text { Mean } \\
\text { AIME }\end{array}$} & \multicolumn{5}{|c|}{ Cumulative Probability of Bequest by Age } & \multirow{2}{*}{$\begin{array}{l}\text { EPDV of } \\
\text { Bequest }\end{array}$} & \multirow{2}{*}{$\begin{array}{l}\text { Ratio of } \\
\text { EPDV of } \\
\text { Bequests }\end{array}$} \\
\hline & & 30 & 40 & 50 & 60 & 67 & & \\
\hline All & 1.000 & 0.012 & 0.035 & 0.064 & 0.120 & 0.200 & $\$ 8,306$ & 1.000 \\
\hline All Whites & 1.058 & 0.009 & 0.027 & 0.053 & 0.105 & 0.182 & $\$ 8,178$ & 0.985 \\
\hline All Blacks & 0.696 & 0.033 & 0.087 & 0.141 & 0.224 & 0.323 & $\$ 8,504$ & 1.024 \\
\hline All Hispanics & 0.714 & 0.012 & 0.035 & 0.064 & 0.120 & 0.200 & $\$ 5,933$ & 0.714 \\
\hline Whites: Coll. + & 1.111 & 0.007 & 0.021 & 0.037 & 0.073 & 0.131 & $\$ 6,197$ & 0.746 \\
\hline Whites: HS + & 1.066 & 0.009 & 0.029 & 0.056 & 0.112 & 0.193 & $\$ 8,776$ & 1.057 \\
\hline Whites: < HS & 0.965 & 0.011 & 0.037 & 0.075 & 0.149 & 0.249 & $\$ 10,205$ & 1.229 \\
\hline Blacks: Coll. + & 0.864 & 0.027 & 0.064 & 0.098 & 0.154 & 0.230 & $\$ 7,512$ & 0.904 \\
\hline Blacks: HS + & 0.733 & 0.033 & 0.087 & 0.142 & 0.227 & 0.328 & $\$ 9,111$ & 1.097 \\
\hline Blacks: < HS & 0.624 & 0.040 & 0.111 & 0.185 & 0.294 & 0.412 & $\$ 9,651$ & 1.162 \\
\hline
\end{tabular}

Notes:

AIME Ratio is the ratio of the mean value of Average Indexed Monthly Earnings for men in each group to the mean AIME of the entire male population as calculated from the Health and Retirement Survey. Cumulative probability of bequest is the probability that an individual dies before the age shown, conditional on being alive at age 22 . EPDV of bequest is the expected discounted value of bequests calculated using equation 5 in text. The discount rate is $3 \%(r=.03)$, individual accounts consist of $6 \%$ of earnings $(\alpha=.06)$, annual earnings at age $22\left(l_{22}\right)$ are $\$ 30,000$ times the AIME ratio, and earnings grow at an annual real rate of $1 \%(\mathrm{~g}=.01)$. "Ratio of EPDV of Bequest" is the ratio of the EPDV of bequests for each group to that of all men.

Source: Authors calculations as described in text. 
TABLE 3

Money's Worth of Real and Nominal Individual Annuities

\begin{tabular}{|c|c|c|c|}
\hline & $\begin{array}{l}\text { Real Annuity } \\
\quad \mathrm{r}=.03\end{array}$ & $\begin{array}{c}\text { Real Annuity } \\
\mathrm{r}=.06\end{array}$ & $\begin{array}{c}\text { Nominal Annuity } \\
r=\pi=.03\end{array}$ \\
\hline \multicolumn{4}{|l|}{ MEN } \\
\hline All & 0.920 & 0.937 & 0.938 \\
\hline All Whites & 0.927 & 0.943 & 0.944 \\
\hline All Blacks & 0.862 & 0.885 & 0.886 \\
\hline All Hispanics & 0.920 & 0.937 & 0.938 \\
\hline Whites: College + & 0.967 & 0.979 & 0.980 \\
\hline Whites: HS + & 0.916 & 0.933 & 0.934 \\
\hline Whites: < HS & 0.865 & 0.888 & 0.889 \\
\hline Blacks: College + & 0.916 & 0.935 & 0.935 \\
\hline Blacks: HS + & 0.857 & 0.880 & 0.881 \\
\hline Blacks: < HS & 0.800 & 0.829 & 0.830 \\
\hline \multicolumn{4}{|l|}{ WOMEN } \\
\hline All & 1.076 & 1.060 & 1.059 \\
\hline All Whites & 1.084 & 1.067 & 1.067 \\
\hline All Blacks & 1.022 & 1.011 & 1.011 \\
\hline All Hispanics & 1.123 & 1.097 & 1.097 \\
\hline Whites: College + & 1.106 & 1.086 & 1.086 \\
\hline Whites: HS + & 1.080 & 1.063 & 1.063 \\
\hline Whites: < HS & 1.044 & 1.031 & 1.031 \\
\hline Blacks: College + & 1.055 & 1.041 & 1.041 \\
\hline Blacks: HS + & 1.022 & 1.012 & 1.011 \\
\hline Blacks: < HS & 0.976 & 0.970 & 0.970 \\
\hline
\end{tabular}

Source: Author's calculations as described in text 
TABLE 4

Initial Monthly Income from Annuities

\begin{tabular}{|l|c|c|c|}
\hline & Real Life Annuity & Real Annuity + 10 PC & Real Annuity + 20 PC \\
\hline Real $(\mathrm{r}=.03)$ & $\$ 621.25$ & $\$ 586.11$ & $\$ 503.35$ \\
\hline Nominal $(\mathrm{r}=.03, \pi=.03)$ & $\$ 808.86$ & $\$ 759.92$ & $\$ 669.29$ \\
\hline
\end{tabular}

Source: Author's calculations as described in text

TABLE 5

Money's Worth of Period Certain Annuity Products

\begin{tabular}{|c|c|c|c|c|c|}
\hline & \multirow{2}{*}{$\begin{array}{l}\text { Real Life } \\
\text { Annuity }\end{array}$} & \multicolumn{2}{|c|}{ Real Annuity + 10 PC } & \multicolumn{2}{|c|}{ Real Annuity + 20 PC } \\
\hline & & $\mu=1$ & $\mu=0$ & $\mu=1$ & $\mu=0$ \\
\hline \multicolumn{6}{|l|}{ MEN } \\
\hline All & 0.920 & 0.936 & 0.868 & 0.972 & 0.745 \\
\hline All Whites & 0.927 & 0.940 & 0.874 & 0.973 & 0.751 \\
\hline All Blacks & 0.862 & 0.900 & 0.813 & 0.964 & 0.698 \\
\hline All Hispanics & 0.920 & 0.936 & 0.868 & 0.972 & 0.745 \\
\hline Whites: College + & 0.967 & 0.965 & 0.912 & 0.978 & 0.783 \\
\hline Whites: HS + & 0.916 & 0.934 & 0.864 & 0.973 & 0.742 \\
\hline Whites: < HS & 0.865 & 0.900 & 0.816 & 0.964 & 0.701 \\
\hline Blacks: College + & 0.916 & 0.932 & 0.864 & 0.970 & 0.742 \\
\hline Blacks: HS + & 0.857 & 0.897 & 0.808 & 0.964 & 0.694 \\
\hline Blacks: < HS & 0.800 & 0.861 & 0.754 & 0.955 & 0.648 \\
\hline \multicolumn{6}{|l|}{ WOMEN } \\
\hline All & 1.076 & 1.061 & 1.015 & 1.026 & 0.872 \\
\hline All Whites & 1.084 & 1.066 & 1.023 & 1.027 & 0.879 \\
\hline All Blacks & 1.022 & 1.025 & 0.964 & 1.018 & 0.828 \\
\hline All Hispanics & 1.123 & 1.097 & 1.060 & 1.042 & 0.910 \\
\hline Whites: College + & 1.106 & 1.080 & 1.043 & 1.030 & 0.896 \\
\hline Whites: HS + & 1.080 & 1.063 & 1.019 & 1.027 & 0.875 \\
\hline Whites: < HS & 1.044 & 1.040 & 0.985 & 1.022 & 0.846 \\
\hline Blacks: College + & 1.055 & 1.046 & 0.995 & 1.023 & 0.855 \\
\hline Blacks: HS + & 1.022 & 1.025 & 0.964 & 1.018 & 0.828 \\
\hline Blacks: < HS & 0.976 & 0.996 & 0.920 & 1.011 & 0.790 \\
\hline
\end{tabular}

Notes: $\mu$ represents the relative value of $\$ 1$ in an estate relative to the value of $\$ 1$ in income to the insured individual.

Source: Author's calculations as described in text. 
TABLE 6

Money's Worth of Joint and Survivor Annuities

\begin{tabular}{|l|c|c|c|c|c|}
\hline & Real Life & \multicolumn{2}{|c|}{ Real Annuity + 10 PC } & \multicolumn{2}{c|}{ Real Annuity + 20 PC } \\
\cline { 3 - 6 } & Annuity & $\mu=1$ & $\mu=0$ & $\mu=1$ & $\mu=0$ \\
\hline $\begin{array}{l}\text { 100\% Survivor } \\
\text { Benefits }\end{array}$ & & & & & \\
\hline All & 1.000 & 1.000 & 0.994 & 1.000 & 0.944 \\
\hline & & & & & \\
\hline All Whites & 1.004 & 1.004 & 0.998 & 1.001 & 0.948 \\
\hline All Blacks & 0.967 & 0.971 & 0.961 & 0.989 & 0.912 \\
\hline All Hispanics & 1.021 & 1.020 & 1.014 & 1.012 & 0.963 \\
\hline & & & & & \\
\hline Whites: College + & 1.019 & 1.016 & 1.012 & 1.005 & 0.961 \\
\hline Whites: HS + & 1.001 & 1.001 & 0.995 & 1.001 & 0.945 \\
\hline Whites: < HS & 0.975 & 0.978 & 0.969 & 0.992 & 0.920 \\
\hline & & & & & \\
\hline Blacks: College + & 0.991 & 0.992 & 0.985 & 0.996 & 0.935 \\
\hline Blacks: HS + & 0.966 & 0.970 & 0.960 & 0.989 & 0.912 \\
\hline Blacks: < HS & 0.932 & 0.941 & 0.926 & 0.979 & 0.879 \\
\hline & & & & & \\
\hline $\begin{array}{l}50 \% \text { Survivor } \\
\text { Benefits }\end{array}$ & & & & & \\
\hline All & 1.000 & 1.000 & 0.943 & 1.000 & 0.809 \\
\hline & & & & & \\
\hline All Whites & 1.008 & 1.008 & 0.950 & 1.001 & 0.815 \\
\hline All Blacks & 0.944 & 0.964 & 0.890 & 0.992 & 0.764 \\
\hline All Hispanics & 1.024 & 1.018 & 0.965 & 1.008 & 0.828 \\
\hline & & & & & \\
\hline Whites: College + & 1.038 & 1.024 & 0.979 & 1.005 & 0.840 \\
\hline Whites: HS + & 1.000 & 1.000 & 0.943 & 1.001 & 0.809 \\
\hline Whites: < HS & 0.956 & 0.971 & 0.902 & 0.993 & 0.774 \\
\hline & & & & & \\
\hline Blacks: College + & 0.987 & 0.991 & 0.931 & 0.997 & 0.799 \\
\hline Blacks: HS + & 0.941 & 0.963 & 0.888 & 0.992 & 0.762 \\
\hline Blacks: < HS & 0.889 & 0.930 & 0.839 & 0.984 & 0.720 \\
\hline
\end{tabular}

Source: Author's calculations as described in text. 
TABLE 7

Probability of Surviving from Age 67 to Age 77

\begin{tabular}{|l|c|c|}
\hline & \multicolumn{2}{|c|}{ Survival Probability from Age 67 to 77 } \\
\hline & Men & Women \\
\hline & & 0.828 \\
\hline All & 0.744 & 0.836 \\
\hline All Whites & 0.751 & 0.779 \\
\hline All Blacks & 0.688 & 0.857 \\
\hline All Hispanics & 0.744 & \\
\hline & & 0.856 \\
\hline Whites: College + & 0.791 & 0.832 \\
\hline Whites: HS + & 0.739 & 0.799 \\
\hline Whites: < HS & 0.693 & \\
\hline & & 0.810 \\
\hline Blacks: College + & 0.744 & 0.779 \\
\hline Blacks: HS + & 0.682 & 0.736 \\
\hline Blacks: < HS & 0.628 & \\
\hline
\end{tabular}

Source: Author's calculations as described in text

TABLE 8

Monthly Income from $\$ \mathbf{1 0 0 , 0 0 0}$ Policy if Priced Based on Group Specific Mortality

\begin{tabular}{|l|c|c|}
\hline & \multicolumn{2}{|c|}{ Monthly Income } \\
\hline & & Women \\
\hline All & $\$ 675.36$ & $\$ 577.36$ \\
\hline & 670.42 & 572.90 \\
\hline All Whites & 720.83 & 608.15 \\
\hline All Blacks & 675.36 & 553.08 \\
\hline All Hispanics & & 561.83 \\
\hline & 642.73 & 575.13 \\
\hline Whites: College + & 678.25 & 595.19 \\
\hline Whites: HS + & 718.40 & \\
\hline Whites: <HS & & 589.01 \\
\hline & 678.22 & 608.01 \\
\hline Blacks: College + & 725.13 & 636.84 \\
\hline Blacks: HS + & 776.92 & \\
\hline Blacks: $<$ HS & & \\
\hline
\end{tabular}

Source: Author's calculations as described in text 